\title{
References
}

1 de Vries G, van Rest J, Meijer W, et al. Low yield of screening asylum seekers from countries with a tuberculosis incidence of <50 per 100000 population. Eur Respir J 2016; 47: 1870-1872.

2 Matteelli A, Lönnroth K, Mosca D, et al. Cameroon's multidrug-resistant tuberculosis treatment programme jeopardised by cross-border migration. Eur Respir J 2016; 47: 686-688.

3 United Nations High Commission for Refugees. Refugees and migrants crossing the Mediterranean to Europe. Overview of arrival trends as of 31 August 2015. http://data.unhcr.org/mediterranean/regional.php Date last accessed: February 4, 2016.

4 Dara M, de Colombani P, Petrova-Benedict R, et al. The minimum package for cross-border TB control and care in the WHO European Region: a Wolfheze consensus statement. Eur Respir J 2012; 40: 1081-1090.

5 Lönnroth K, Migliori GB, Abubakar I, et al. Towards tuberculosis elimination: an action framework for low-incidence countries. Eur Respir J 2015; 45: 928-952.

6 Getahun H, Matteelli A, Abubakar I, et al. Management of latent Mycobacterium tuberculosis infection: WHO guidelines for low tuberculosis burden countries. Eur Respir J 2015; 46: 1563-1576.

7 D'Ambrosio L, Dara M, Tadolini M, et al. Tuberculosis elimination: theory and practice in Europe. Eur Respir J 2014; 43: 1410-1420.

8 Coker R, Bell A, Pitman R, et al. Tuberculosis screening in migrants in selected European countries shows wide disparities. Eur Respir J 2006; 27: 801-807.

9 Klinkenberg E, Manissero D, Semenza JC, et al. Migrant tuberculosis screening in the EU/EEA: yield, coverage and limitations. Eur Respir J 2009; 34: 1180-1189.

10 Schneeberger Geisler S, Helbling P, Zellweger JP, et al. Screening for tuberculosis in asylum seekers: comparison of chest radiography with an interview-based system. Int J Tuberc Lung Dis 2010; 14: 1388-1394.

\section{Preventing and controlling tuberculosis among refugees in Europe: more needed for high-risk populations}

\section{From the authors:}

We thank M. Dara and colleagues for their commentary on our article "Low yield of screening asylum seekers from countries with a tuberculosis (TB) incidence of $<50$ per 100000 population" [1]. We agree that the current high influx of refugees from both low- and high-incidence countries into countries that already have a TB incidence $<10$ per 100000 population, e.g. many European Union member states, brings up a number of new challenges.

We agree with M. Dara and colleagues that profiles of migrating populations differ, as determined for example by country of origin or reasons for migration, such as study, employment, family reunification or war. In the Netherlands, screening processes differ for recently arrived migrants and refugees and the effectiveness of these interventions is evaluated separately. Results of chest radiography screening of (regular) migrants were previously analysed for the period 2005-2010 [2]. Overall, 108 TB cases were diagnosed among 117389 screened migrants, resulting in a TB prevalence of 92 per 100000 screened persons (95\% CI 75-109). Only seven cases were identified by screening of 31218 migrants from countries with a TB incidence of $<50$ per 100000 , resulting in a TB prevalence of 22 per 100000 screened persons (95\% CI 9-46) and a number needed to screen (NNS) of 4460 . We would like to reiterate that the Netherlands uses a threshold of 2000 for NNS, in order to limit exposure of healthy individuals to radiation. The low yield among (regular) migrants from countries with a TB incidence of $<50$ per 100000 led to the advice to the Ministry of Health to limit screening to migrants from countries with an estimated TB incidence of $>50$ per 100000 population. This has been in effect since January 1, 2015. Our current evaluation of screening asylum seekers ( January 2011-September 2015) from countries with a TB incidence of $<50$ per 100000 had similar results, i.e. a TB prevalence of 26 per 100000 screened persons (95\% CI 14-45) and a NNS of 3787, and the same consideration led to the advice to the Ministry of Health to stop screening. We agree that our results cannot be automatically extrapolated to other countries and would be interested to read other countries' experiences. However, our results are not unexpected in asylum seekers from countries with traditionally a low TB incidence. Even if their circumstances dramatically change and they are staying in densely populated camps, there will initially still be few cases that transmit the disease. 
The second issue raised by M. Dara and colleagues is latent TB infection (LTBI). We agree that for low-incidence countries moving towards pre-elimination, apart from early case-finding and adequate treatment, LTBI screening is a further and complementary intervention to reduce TB incidence [3]. Especially individuals at the highest risk of developing the disease, such as contacts of pulmonary TB patients and those with clinical risk factors such as HIV, anti-tumour necrosis factor treatment, dialysis, organ or haematological transplantation and silicosis, should benefit from LTBI screening and preventive treatment [4]. In our opinion, low-incidence countries considering LTBI screening of certain groups of migrants and asylum seekers should target this intervention to persons from high-incidence countries according to World Health Organization (WHO) guidelines [4], WHO country incidence estimates [5] or based on information from their national surveillance systems. We recently described the TB situation among the two largest groups of asylum seekers in the Netherlands over the period January 2013-September 2015 [6]. Among Syrian asylum seekers, TB prevalence was 22 per 100000 screened persons at arrival and TB incidence was 19 per 100000 in the first year after arrival, in agreement with WHO estimates for Syria. Among Eritrean/Ethiopian asylum seekers, TB prevalence was 283 per 100000 screened persons at arrival and TB incidence was 1394 per 100000 in the first year after arrival, highly inconsistent with the WHO estimates for Eritrea of 78 per 100000 population in 2014 . $78 \%$ of the Eritrean/Ethiopian asylum seekers $(n=3295)$ in 2014 arrived in the second quarter and by September 30, 2015, 0.3\% (11 cases) were diagnosed with TB at screening upon arrival; $1.6 \%$ developed TB in the first year after arrival (54 cases) and $0.3 \%$ so far in the second year after arrival (11 cases), in total $2.3 \%$ of this cohort. We hypothesised that, apart from high transmission rates and occasional HIV seropositivity, poor nutrition and stress may have contributed to this very high TB rate. This study shows clearly that we should prioritise and offer LTBI screening and preventive treatment to such high-risk populations.

It is unrealistic to expect $\mathrm{TB}$ control programmes in low-incidence countries to receive much more funding when the incidence is declining. In the Netherlands, over recent years, several chest radiography screening programmes have become more targeted to improve effectiveness, mainly based upon evaluation of yield, i.e. prevalence rates. Now, $<50 \%$ of the prison population is screened and screening of migrants and asylum seekers from countries with a TB incidence of $<50$ per 100000 has been stopped or will be stopped. Another example is chest radiography screening of drug users and homeless persons, which was replaced by LTBI screening in Amsterdam and stopped after controlling the outbreak in Rotterdam [7]. The challenge in the Netherlands and other low-incidence countries is to redirect the TB programme and resources from screening for active disease towards targeted LTBI screening to optimise epidemiological impact.

The Dutch National TB Control Plan 2016-2020 recommends targeting LTBI screening to child migrants and child asylum seekers and to persons from countries with a TB incidence $>200$ per 100000 [8]. In the latter case, initial LTBI screening will replace the follow-up chest radiography screening that is still carried out in the Netherlands at regular intervals. The National TB Control Plan also advises evaluation of the implementation, impact and cost-effectiveness of LTBI screening of these groups of migrants and asylum seekers before scaling it up to other migrant groups. The efficiency of TB and LTBI screening of migrants and asylum seekers, as well as of other TB control interventions, will be the subject of a meeting planned in 2018 between the Ministry of Health and various stakeholders to discuss "allocative efficiency", as was recommended by the last country review [9].

LTBI management in well-defined groups is an essential component of TB elimination plans [3]. Implementation of LTBI screening and preventive treatment is not yet fully implemented in European low-incidence countries and needs to be scaled up [10]. Thus, it is recommended for European countries to work more intensively, prepare consolidated plans and ensure available resources to move towards elimination [10].

In conclusion, we agree with M. Dara and colleagues, that "more is needed", such as LTBI screening of migrants and asylum seekers, but only for those with a high risk of TB. Moreover, low-incidence countries will benefit most from progress made in high TB incidence countries and thus, instead of overspending large amounts of money to prevent a few cases among migrants and asylum seekers with relatively low risk of $\mathrm{TB}$, we recommend supporting $\mathrm{TB}$ control in high-incidence countries.

@ERSpublications

Screening asylum seekers from high TB incidence countries for LTBI is recommended in low-incidence countries http://ow.ly/4nbKhU

Gerard de Vries ${ }^{1,2}$, Job van Rest ${ }^{1}$, Wieneke Meijer ${ }^{3}$, Bert Wolters ${ }^{4}$, Rob van Hest ${ }^{4,5}$ and Michael Kimerling ${ }^{1}$ ${ }^{1}$ KNCV Tuberculosis Foundation, The Hague, The Netherlands. ${ }^{2}$ Centre for Infectious Diseases Control, National Institute for Public Health and the Environment, Bilthoven, The Netherlands. ${ }^{3}$ Dept of TB Control, Municipal Public Health Services Amsterdam, Amsterdam, The Netherlands. ${ }^{4}$ Dept of TB Control, Municipal Public Health Services Groningen, Groningen, The Netherlands. ${ }^{5}$ Dept of TB Control, Municipal Public Health Services Rotterdam-Rijnmond, Rotterdam, The Netherlands. 
Correspondence: Gerard de Vries, KNCV Tuberculosis Foundation, P.O. Box 146, 2501 CC The Hague, The Netherlands. E-mail: gerard.devries@kncvtbc.org

Received: March 202016 | Accepted: April 182016

Conflict of interest: None declared.

\title{
References
}

1 de Vries G, van Rest J, Meijer W, et al. Low yield of screening asylum seekers from countries with a tuberculosis incidence of $<50$ per 100000 population. Eur Respir J 2016; 47: 1870-1872.

2 van Rest JF, Erkens CGM, de Vries G. Evaluatie tuberculosescreening immigranten. Resultaten binnenkomst- en vervolgscreening op tuberculose van immigranten in de jaren $2005 \mathrm{t} / \mathrm{m}$ 2010. [Evaluation of tuberculosis screening of immigrants. Results of entry and follow-up tuberculosis screening of immigrants 2005-2010]. The Hague, KNCV Tuberculosis Foundation, 2012. www.kncvtbc.org/uploaded/2016/01/evaluatie_tuberculosescreening immigranten_2005-2010.pdf

3 Lönnroth K, Migliori GB, Abubakar I, et al. Towards tuberculosis elimination: an action framework for low-incidence countries. Eur Respir J 2015; 45: 928-952.

4 Getahun H, Matteelli A, Abubakar I, et al. Management of latent Mycobacterium tuberculosis infection: WHO guidelines for low tuberculosis burden countries. Eur Respir J 2015; 46: 1563-1576.

5 World Health Organization. Global Tuberculosis Report 2015. WHO/HTM/TB/2015.22. Geneva, World Health Organization, 2015. www.who.int/tb/publications/global_report/gtbr15_main_text.pdf

6 de Vries G, Gerritsen RF, van Burg JL, et al. Tuberculose bij asielzoekers in Nederland: descriptief onderzoek onder de 2 grootste groepen asielzoekers [Tuberculosis among asylum-seekers in the Netherlands: a descriptive study among the two largest groups of asylum-seekers]. Ned Tijdschr Geneeskd 2016; 160: D51.

7 van Hest R, de Vries G. Active tuberculosis case-finding among drug users and homeless persons: after the outbreak. Eur Respir J 2016; 48: 269-271.

8 de Vries G, Riesmeijer R. National Tuberculosis Control Plan 2016-2020. Towards Elimination. Bilthoven, National Institute for Public Health and the Environment (RIVM), 2016. www.kncvtbc.org/uploaded/2016/04/ National-Tuberculosis-Control-Plan-2016-2020.-Towards-elimination.pdf

9 World Health Organization, European Centre for Disease Prevention and Control. Report of the Joint WHO and ECDC Programme Review of the National TB Control Programme in the Netherlands. 30 September-4 October 2013. Copenhagen, WHO Regional Office for Europe, 2014. www.euro.who.int/_data/assets/pdf_file/0006/ 255354/Report-of-the-joint-WHO-and-ECDC-programme-review-of-the-national-TB-control-programme-in-theNetherlands.pdf

10 D'Ambrosio L, Dara M, Tadolini M, et al. Tuberculosis elimination: theory and practice in Europe. Eur Respir J 2014; 43: 1410-1420.

\section{Treatment options for isolated locoregional recurrences of nonsmall cell lung cancer after surgery: yes, radiation therapy too!}

\author{
To the Editor:
}

In a recent article, Suвотіс et al. [1] summarised the importance of salvage surgery in treating local or loco-regional, post-surgical recurrences in patients with, mostly, early stage nonsmall cell lung cancer (NSCLC). While the feasibility of such an approach is indisputable, we believe that the readership of the European Respiratory Journal should be made aware of another treatment option already successfully used in this setting, namely, radiation therapy. This is especially important in patients with less favourable features, where secondary surgery may not be an option. Other authors have already shown that such patients comprise the majority of the patient population, with salvage surgery being possible in just $4 \%$ of cases. Taking this into consideration may give the treating physicians a better perspective and also enable a more meaningful discussion on optimising both the standard clinical and investigational approaches in any future endeavours in this setting.

Traditionally, loco/regional recurrence may be divided into chest wall/pleural, parenchymal, bronchial stump, mediastinal lymph node recurrence or a combination of any of these. Radiation therapy has already been successfully used previously in all of the aforementioned settings and its value in the treatment of 